Science, Technology and Development 34 (2): 94-100, 2015

ISSN 0254-6418 / DOI: 10.3923/std.2015.94.100

(c) 2015 Pakistan Council for Science and Technology

\title{
Effect of Alternative Nutrient Sources During Anaerobic Degradation of Potato Wastewater
}

\author{
Ignacio Durruty and Jorge Froilán González \\ Group of Biochemical Engineering, Department of Chemical Engineering, Faculty of Engineering, \\ National University of Mar del Plata, Juan B. Justo, 4302 (7600), Mar del Plata, Bs. Aires, Argentina
}

\begin{abstract}
The supplementation of nutrients on biological wastewater treatment in many cases may become a relevant part of the treatment cost. In that sense, the finding of new efficient and economic nutrient sources is very important in large scale industrial applications. This work reports on the effect of four readily available alternative nutrient sources during anaerobic degradation of potato wastewater: Peptone, soybean meal, sludge from an aerobic wastewater treatment plant (aerobic sludge) and $\mathrm{NH}_{4} \mathrm{NO}_{3}$ plus Micronutrient Supplementation (MS). The addition of alternative nutrient sources changed the rate limiting step from the last steps to hydrolysis in all the cases. While the added soybean meal allowed obtaining the higher final conversion, the degradation rate was slower than the non-supplemented control. The assays with $\mathrm{NH}_{4} \mathrm{NO}_{3}+\mathrm{MS}$ as nitrogen source presented the highest degradation rate. Moreover both $\mathrm{NH}_{4} \mathrm{NO}_{3}$ and $\mathrm{MS}$ are needed to improve the degradation rates. The percentage of residual COD after treatment was similar for peptone, aerobic sludge and $\mathrm{NH}_{4} \mathrm{NO}_{3}+\mathrm{MS}$ test. However, the lowest percentage of residual soluble COD was obtained when the aerobic sludge was used as supplement. The aerobic sludge presented $\mathrm{Co}$ and Mo deficiencies. Finally, taking into account the advantages and disadvantages discussed, among those tested, the aerobic sludge seems to be the best alternative nutrient source for industrial applications.
\end{abstract}

$\underline{\text { Key words: Anaerobic digestion, nitrogen, industrial application, micronutrients }}$

\section{INTRODUCTION}

Potato industry wastewaters are currently subject to biological digestion, both aerobic (Lasik et al., 2010) and anaerobic (Fang et al., 2011) to reduce the organic pollution load. Although, anaerobic digestion processes have been carried out for decades, interest in the economic recovery of methane gas from industrial and agricultural wastewaters has recently increased due to the changing socio-economic situation in the world (Nishio and Nakashimada 2007). Besides, biological treatment appears to be a promising technology to attain revenue from Certified Emission Reduction (CER) credits, more commonly known as carbon credits from the Clean Development Mechanism (CDM) as methane gas is generated from anaerobic digestion and can be utilized as renewable energy (Chan et al., 2009).

The supplementation of nutrients on biological wastewater treatment is generally needed and usually becomes an important cost on anaerobic degradation (Grady et al., 1999). The lack of understanding or underestimating nutrient requirements of methanogens could be a serious problem in commercial applications of anaerobic biotechnology as well (Speece, 1983). In particular, macronutrients requirement is an important factor that affects the microbial processes since it affects directly the biomass growth (Gerardi, 2003). The lack of nitrogen and phosphorous availability could cause reactor failure. Therefore, the availability of macro nutrients is of paramount importance in biogas digester as well (Demirel and Scherer, 2008). The effect of nitrogen and phosphorous was widely studied in aerobic degradation (Krishnan et al., 2008). However, the studies referred to nutrients requirements during anaerobic treatment generally only fall into the influence of trace metals (Demirel and Scherer, 2011; Cresson et al., 2006; Lo et al., 2012; Zandvoort et al., 2006; Munk et al., 2010) and rarely studied the nitrogen or phosphorous requirements and its sources (Britz et al., 1988; Sterling et al., 2001; Scherer et al., 2009).

In that sense, the finding of new efficient and economic nutrient sources is of great importance to proper management of large scale industrial applications. This study shows the effect of alternative nutrient sources during anaerobic degradation of potato wastewater and evaluates them from a cost-efficiency point of view. Finally, deficiencies in trace metals are also tested.

Corresponding Author: Ignacio Durruty, Group of Biochemical Engineering, Engineering School, National University of Mar del Plata, Juan B. Justo 4302, CP. 7600, Mar del Plata Tel: 54-223-481-6600/261 Fax: 54-223-481-0046 


\section{MATERIALS AND METHODS}

The potato Wastewater (WW) was the same used on previous works (Durruty et al., 2012). Sludge from a methanogenic industrial digester was used as inoculum, it was kindly supplied by McKein SA (Balcarce, Argentina), from its anaerobic wastewater treatment plant. The inoculum-substrate ratio was fixed as 5\% v/v which is the same used in the industrial digester.

Five $0.2 \mathrm{~L}$ batch tests were performed simultaneously in order to evaluate the effect of four alternative nutrient sources on anaerobic degradation. The experimental scheme is depicted on Fig. 1. All the tests were performed at least by duplicate and inoculated with $10 \% \mathrm{v} / \mathrm{v}$ of anaerobic sludge. The $\mathrm{pH}$ was fixed to 7.2 with buffer phosphate, ensuring the phosphorous requirement. This $\mathrm{pH}$ value is within the optimum range of the different strains involved on process (Gerardi, 2003).

The first reactor was filled with $0.1 \mathrm{~L}$ of Wastewater (WW) and 0.1 L of inoculated buffered distilled water as control. The second one was filled with $0.1 \mathrm{~L}$ of WW and $0.1 \mathrm{~L}$ of inoculated buffered solution of peptone. The peptone and yeast extract are usually used in lab scale to ensure nutrient requirements during biological growth (Gerardi, 2003). The third reactor was filled with $0.1 \mathrm{~L}$ of WW and $0.1 \mathrm{~L}$ of inoculated buffered suspension containing soybean meal. The soybean meal is a by-product of soybean industry, rich on nitrogen and minerals. It is cheap and it is readily available in agricultural zones where the potato industries are generally located. The fourth one was filled with $0.1 \mathrm{~L}$ of
WW and $0.1 \mathrm{~L}$ of inoculated buffered distilled water containing $25 \mathrm{~mL}$ of aerobic sludge from an aerobic Wastewater Treatment Plant (WWTP). Since generally the anaerobic treatment requires an aerobic post-treatment to achieve the disposal standards (Chan et al., 2009) and the aerobic treatment generates an important amount of aerobic sludge (Nishio and Nakashimada, 2007), which contains nitrogen and trace metals, this aerobic sludge constitutes an economic choice for supply of nutrients on anaerobic treatment while at the same time it is stabilized. The aerobic sludge used was obtained from aerobic post-treatment plant from the same WWTP than the anaerobic activated sludge. The fifth one was filled with $0.1 \mathrm{~L}$ of wastewater and $0.1 \mathrm{~L}$ of inoculated buffered solution containing Micronutrient Supplementation (MS) and $\mathrm{NH}_{4} \mathrm{NO}_{3}$. The micronutrients were supplied adding $0.1 \% \mathrm{v} / \mathrm{v}$ of commercially available trace quelated elements solution composed by $\operatorname{Mg}$ (6.1 g L $\left.{ }^{-1}\right)$, Mn (15 g L $\left.{ }^{-1}\right)$, Cu (2.5 $\left.\mathrm{g} \mathrm{L}^{-1}\right)$, Zn (20 $\left.\mathrm{g} \mathrm{L}^{-1}\right)$, Fe $\left(20 \mathrm{~g} \mathrm{~L}^{-1}\right)$, B $\left(7.5 \mathrm{~g} \mathrm{~L}^{-1}\right)$, Mo $\left(0.25 \mathrm{~g} \mathrm{~L}^{-1}\right)$ and Co $\left(0.025 \mathrm{~g} \mathrm{~L}^{-1}\right)$. The commercial micronutrients solution is formulated for crops and it is available in agricultural zones where the potato industries are generally located.

In all the test the ratio COD/N/P was fixed at 200/5/1 according to Krishnan et al. (2008) to avoid nitrogen deficiencies. The COD and $\mathrm{N}$ as total nitrogen were measured via colorimetric $\mathrm{HACH}{ }^{\circledR}$ tests. The total and volatile suspended solids were determined according to APHA (1998). Table 1 summarizes the conditions in the 5 tests.

Table 1: Experimental set point for different batch test

\begin{tabular}{|c|c|c|c|c|c|c|}
\hline Batch No. & Nutrient source & Initial COD $\left(\mathrm{mg} \mathrm{L}^{-1}\right)$ & Soluble & Solid & Initial TN (mg L $\left.{ }^{-1}\right)$ & Additional cost (U\$S $\left.\mathrm{m}^{-3} \mathrm{WW}\right)$ \\
\hline 1 & None (control) & 6613 & 2598 & 4015 & 16 & - \\
\hline 2 & Peptone & 8363 & 4321 & 4042 & 165 & 1600 \\
\hline 3 & Soybean meal & 8843 & 3432 & 5411 & 166 & 1 \\
\hline 4 & Aerobic sludge & 79934 & 2623 & 5370 & 177 & 0 \\
\hline 5 & $\mathrm{NH}_{4} \mathrm{NO}_{3}+\mathrm{MS}$ & 6493 & 2595 & 3898 & 169 & 23 \\
\hline
\end{tabular}

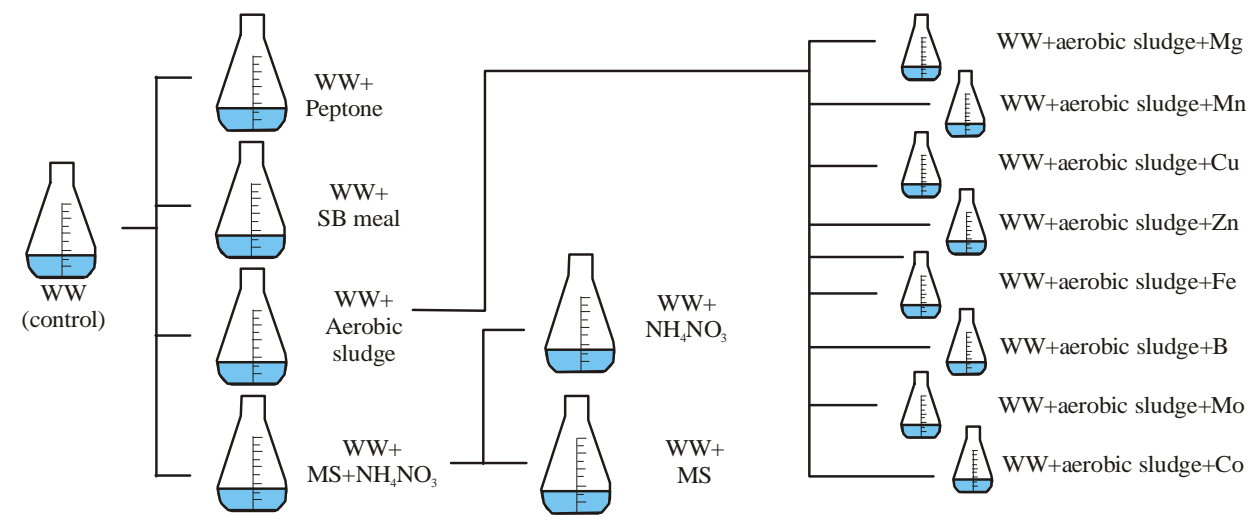

Fig. 1: Experimental scheme. Test of the 4 alternative nutrient sources, discrimination between effects due to $\mathrm{NH}_{4} \mathrm{NO}_{3}$ and MS and finally the study of micronutrient deficiencies for aerobic sludge as a nutrient source 


\section{RESULTS AND DISCUSSION}

In Table 1, it can be seen that the addition of some nutrient sources implied an increase in the organic load. The peptone has a $5 \% \mathrm{w} / \mathrm{w}$ of nitrogen and easily degradable organic soluble load while the soybean meal has almost $10 \% \mathrm{w} / \mathrm{w}$ of nitrogen, mostly in a non-soluble particulate form. The aerobic sludge has a $0.2 \% \mathrm{w} / \mathrm{v}$ of nitrogen and led to an increase in solid organic load. The $\mathrm{NH}_{4} \mathrm{NO}_{3}$ has $35 \% \mathrm{w} / \mathrm{w}$ of nitrogen and did not increase the COD, however, as it did not provide any other nutrient, MS was added to supply trace elements requirements (Lo et al., 2012). It has been reported that the ammonia concentration has to be kept in excess of at least $40-70 \mathrm{mg} \mathrm{L} \mathrm{L}^{-1}$, to prevent reduction of bacterial activity (Takashima and Speece, 1989). Furthermore, it was reported that the optimum conditions for Methanosaeta concilii which is the most ammonia-sensitive methanogen, were in the range of 195-860 mg L ${ }^{-1}$ (Steinhaus et al., 2007). The Table 1 shows that the WW without supplementation falls below the minimum concentration proposed by Takashima and Speece (1989) highlighting the need of nitrogen addition. This phenomenon was previously reported for a similar organic source (beet without leaves) (Demirel and Scherer, 2008). On the other hand, the supplemented batches meet the requirement and fall far below the maximum reported by Steinhaus et al. (2007).

The Fig. 2 shows the solid (particulate) and soluble COD evolution for the tests using different alternative nutrient sources. In most studies about anaerobic degradation with suspended organic matter, the rate-limiting step is the hydrolysis of solids (Vavilin et al., 2008). However, some researches (Siles et al., 2008; Neves et al., 2006) have reported that the degradation of the particulate organic load was not the limiting factor. The accumulation of soluble COD during the control test (Fig. 2a) demonstrates that the degradation of soluble organic load is slower than the degradation of the particulate organic load. However, the addition of alternative nutrient sources (Fig. 2b-e) avoided this accumulation indicating that the hydrolysis became the slowest step. In the particular case of soybean meal (Fig. 2c), this change is due to the slower solid degradation rate. The nutrients are captured inside the solid matrix that must be first hydrolyzed to become available to the microorganisms. Besides, the soybean meal added solid organic load different from that the potato starch which the hydrolytic bacteria should also consume. These phenomena lead to a reduction in the solid COD degradation rate. Finally, in the cases of peptone addition (Fig. 2b), aerobic sludge (Fig. 2d) or $\mathrm{NH}_{4} \mathrm{NO} 3+\mathrm{MS}$ (Fig. 2e), the change in relatives rates is due to the higher soluble degradation. In these cases the easily available nutrients accelerated the latest steps during anaerobic degradation biomass production and methane generation (Gerardi, 2003).

The Biochemical Methane Potential (BMP) is an important parameter for assessing design, economic and managing issues for the full-scale implementation of the anaerobic digestion process (Eiroa et al., 2012). However, in this study the BMP on different assays did not show differences. The value obtained for BMP was $0.35 \mathrm{~g}$ $\mathrm{COD}-\mathrm{CH}_{4} / \mathrm{g} \mathrm{COD}_{\text {degraded }}$ and the difference on methane production on every case are intimately linked to COD degradation. Figure 3 shows the normalized degradation of total organic load as fraction of the total residual COD. This figure shows that the addition of $\mathrm{NH}_{4} \mathrm{NO}_{3}+\mathrm{MS}$ accelerated the initial degradation (first two weeks) more than the addition of peptone or aerobic sludge and more than non-supplemented control. The addition of soybean meal presented a deleterious effect over the total degradation rate due to the reduction at the earlier step of the degradation discussed above. However, the final residual COD percentage was the lowest. It is relevant to note that although the addition of this nutritional source resulted in the lowest degradation rate, the percentage of removal was the highest.

The improvement of the degradation rate in $\mathrm{NH}_{4} \mathrm{NO}_{3}+\mathrm{MS}$ assay is attributed to the following factors: (a) The easily bio-available nitrogen source: Bryant and Robinson (1961) have demonstrated that none of single nitrogen compounds tested in their study would increase growth of the studied strains above that obtained with a growth-limiting concentration of ammonia. (b) The presence of micro-nutrients: the availability or lack of trace elements such as Fe, Co, Ni, Zn and Mo definitely plays a significant role in maintaining a stable and an efficient conversion process in a biogas digester (Demirel and Scherer, 2011). Besides to the bioavailability of metals, the scale of application and the type of substrate used also play a crucial role in the supply of trace metals during anaerobic digestion (Lo et al., 2012). With the aim to discriminate between these possible causes, an additional set of tests was performed with one batch with $\mathrm{NH}_{4} \mathrm{NO}_{3}$ and without MS and the other without $\mathrm{NH}_{4} \mathrm{NO}_{3}$ but with MS. The addition of nitrogen alone did not present differences respect to control. On the other hand, the addition of MS alone yielded a faster degradation than the control but slower than the batch with $\mathrm{NH}_{4} \mathrm{NO}_{3}+\mathrm{MS}$. This clearly demonstrates that the improvement on degradation rates discussed above is due to both the addition of trace metals and nitrogen supply, demonstrating that the original wastewater has deficiencies in both macro and micro nutrients.

Since, the solid residual load could be removed in a further post-treatment step by mechanical means it is 
Sci. Technol. Dev., 34 (2): 94-100, 2015
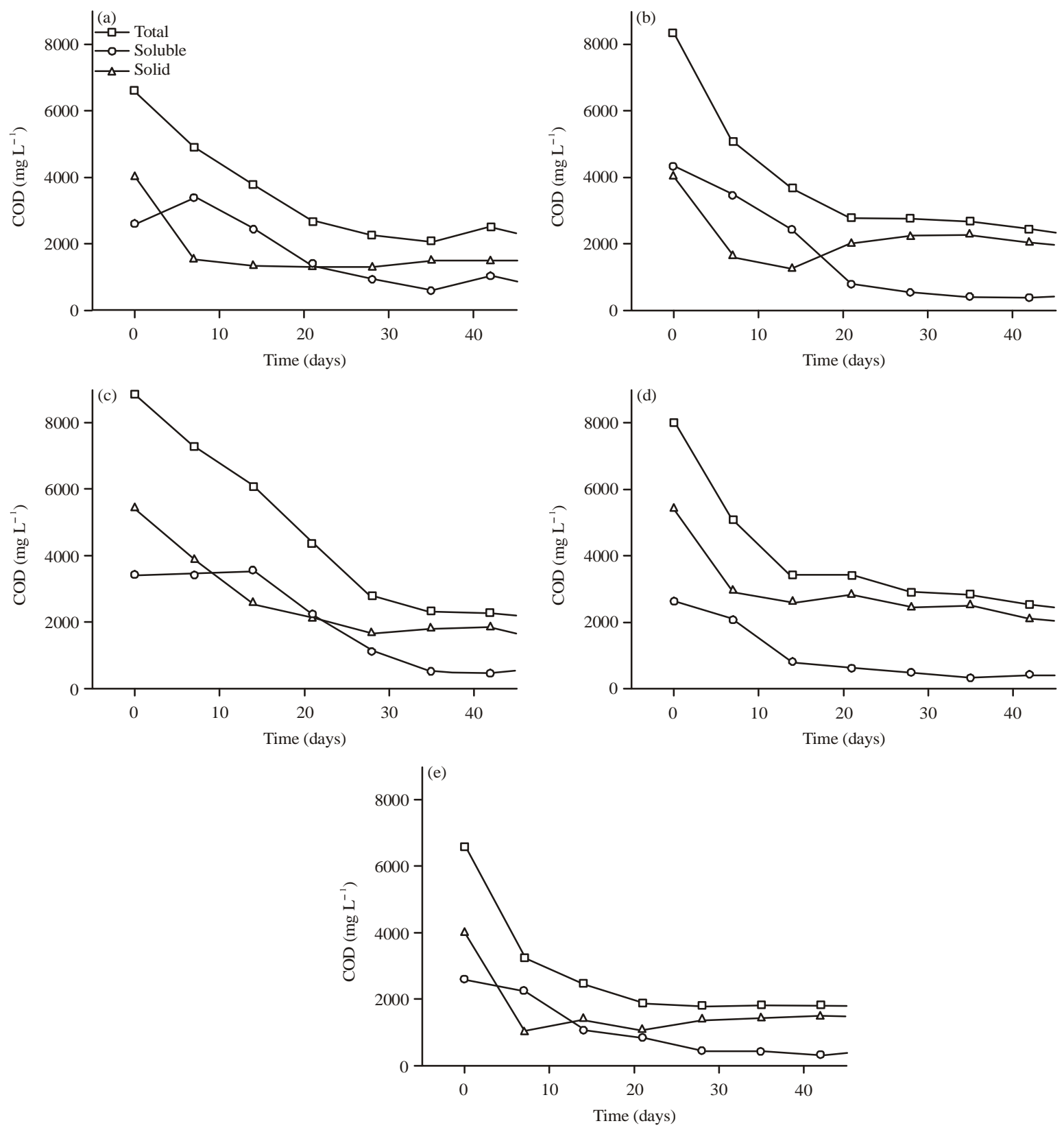

Fig. 2(a-e): COD versus time for alternative nitrogen sources and control, (a) Control, (b) Peptone, (c) Soybean meal, (d) Aerobic sludge and (e) $\mathrm{NO}_{3} \mathrm{NH}_{4}+\mathrm{MS}$

important to study the effects of different sources in residual soluble loads. Figure 4 shows how the percentage of residual soluble COD is lower in all the supplemented tests, although is the lowest in the test supplemented with aerobic sludge.

In turn, the solid residual organic load is directly related with the biomass produced during the process, since a previous study (Durruty et al., 2012) has revealed that this wastewater did not have a particulate inert fraction. The highest percentage of residual solid COD is present in the aerobic sludge supplemented test. This is because a fraction of the solid COD provided by the aerobic sludge by-passed the treatment and remained in the effluent. The percentage of biomass produced (\% solid residual COD) respect to the original total COD load, analogous to the conventional biomass yield coefficient, differs depending to the supplement used: in the peptone supplemented test and in the micronutrient supplemented test is around $22 \%$, while in the soybean meal supplemented test the final biomass rounds the $16 \%$ of the 
Sci. Technol. Dev., 34 (2): 94-100, 2015

Table 2: Advantages and disadvantages from alternative nitrogen sources

\begin{tabular}{lll}
\hline Nutrient sources & Advantages & Disadvantages \\
\hline Peptone & High degradation rate & $\begin{array}{l}\text { Very high cost } \\
\text { Increase in initial soluble organic load }\end{array}$ \\
& $\begin{array}{l}\text { Lowest final soluble organic load } \\
\text { Lowean final solid organic load } \\
\text { Aerobic sludge }\end{array}$ & $\begin{array}{l}\text { Low degradation rate } \\
\text { Increase in initial particulate organic load }\end{array}$ \\
& $\begin{array}{l}\text { Zero cost } \\
\text { Lowest final soluble organic load }\end{array}$ & High final solid organic load (sludge) \\
& High degradation rate & \\
& Alternative treatment to stabilize aerobic sludge initial particulate organic load \\
$\mathrm{NH}_{4} \mathrm{NO}_{3}+$ Micronutrient supplement & \\
& Highest degradation rate & \\
& No increment on initial organic load & High cost \\
& & Complex storage- explosion risk. \\
& Needed of trace metals supplementation \\
\hline
\end{tabular}

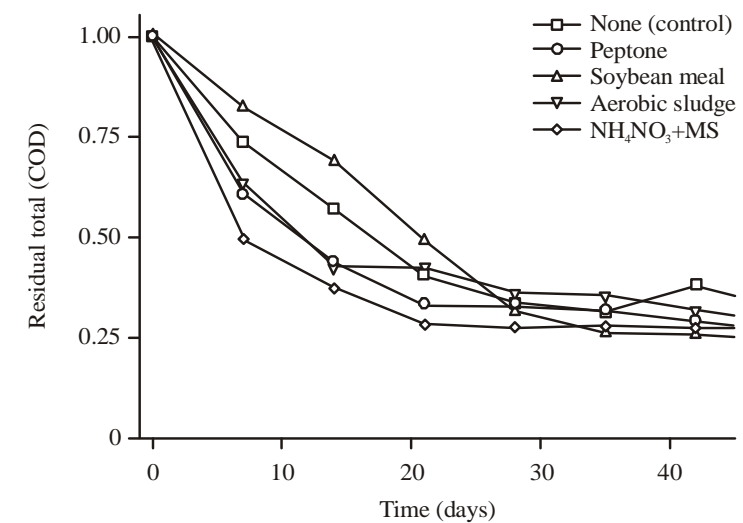

Fig. 3: Total residual COD expressed as fraction of total initial COD versus time for alternative nutrient sources and control

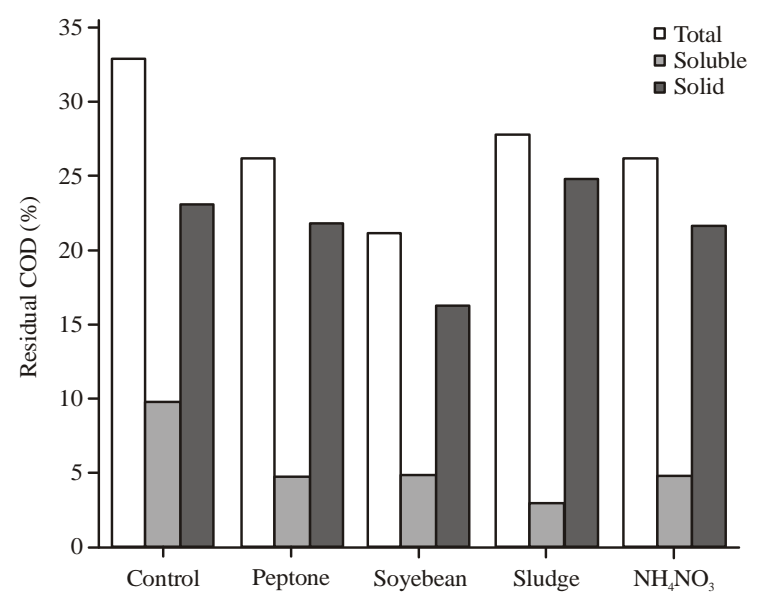

Fig. 4: Final total, solid and soluble residual COD expressed as percent of total initial COD for alternative nutrients sources and control

original COD load. This lower value of biomass yield together with the lowest hydrolysis rate explains the slow global degradation rate. The highest value of final biomass expressed as percentage of initial COD was found in the aerobic sludge supplemented test. This leads to the need for treating and stabilizing excess of biomass.
Table 2, summarizes the above discussed advantages and disadvantages of alternative nutrient sources. Among the presented choices, the activated sludge minimized the cost, allowed a good degradation rate and presented the lowest final soluble organic load. On the other hand its disadvantages were related with the high amount of particulate organic load both in the inlet and the outlet streams. However, this alternative was presented as a solution to treat and stabilize aerobic sludge, the high particulate organic load is a preexistent issue which in this way is partially solved and does not imply a new problem. In conclusion, the aerobic sludge seems to be the most suitable alternative nutrient source for industrial applications among those tested.

Finally, with the aim to evaluate micro-nutritional deficiencies when the aerobic sludge is used as nutritional supplement an extra set of tests was performed as shown (Fig. 1). Several simultaneous batch tests were carry out containing WW, aerobic sludge and each of the trace metals contained on MS individually (control has only WW plus aerobic sludge). When Mg, Mn, Zn, Cu, Fe or $\mathrm{B}$ were added individually the degradation rates did not present differences from the control indicating the lack of need of these trace metals. The obtained result indicates that these metals were present in nutrient supplement (aerobic sludge) or potato wastewater since they are indispensable to carry out anaerobic degradation (Demirel and Scherer, 2011). This phenomenon was previously observed in other works (Kumar et al., 2006; Sager, 2007).

In our tests, the additions of Mo and Co improved individually the degradation rate with respect to that of the control. This indicates the insufficiency of these elements on aerobic sludge together with a high dependence of these metals during anaerobic degradation. Several authors have studied the effect of Co on anaerobic degradation (Jarvis et al., 1997; Lebuhn et al., 2008; Pobeheim et al., 2011; Qiang et al., 2012). Furthermore Co was reported to be the most limiting element (Lebuhn et al., 2008). The high importance of this metal is due to the fact that cobalt is the central ion of corrinoids (vitamin $\mathrm{B}_{12}$ derivatives), involved in methyl transfers in methanogenesis and is present in both 
hydrogenotrophic and acetotrophic methanogens (Jarvis et al., 1997). In addition, the methyl-H4SPT: coenzyme M Methyltransferase complex contains cobalt (Pobeheim et al., 2011). Fewer works studied the effect of Mo on anaerobic degradation (Worm et al., 2009; Lebuhn et al., 2008). Lebuhn et al. (2008) reported that Mo was a limiting element, along with Co and Se. Most of methanogenic bacteria contain formate dehydrogenases. The catalytic centers of this enzyme contain molybdenum or tungsten as metal-binding cofactors that are essential for their catalytic function (Worm et al., 2009). Furthermore, depletion of molybdenum and tungsten was described to decrease formate dehydrogenase activity in defined syntrophic growth of the propionate oxidizing Syntrophobacter fumaroxidans and methanogenic Methanospirillum hungatei (Plugge et al., 2009). Therefore, the lack of molybdenum, tungsten or selenium during an anaerobic biological process could thus result in a decrease of the propionate consumption (intermediate reaction) and ultimately lead to process failure.

\section{CONCLUSION}

In this study, it has been demonstrated that the original potato processing WW presents a deficiency in nutrients and it needs to be supplemented to improve the efficiency of process. In that sense the addition of all of the alternative nutrient sources tested causes the hydrolysis to the slowest reaction instead of the last steps. The cost-efficiency analysis showed that the aerobic sludge appears as the better choice to manage properly the anaerobic degradation of potato processing wastewater. The activated sludge minimized the cost, allowed a good degradation rate and presented the lowest final soluble organic load. Furthermore, this alternative was presented as a solution to treat and stabilize aerobic sludge. Further improvement can be achieved by adding Co and Mo.

\section{REFERENCES}

APHA., 1998. Standard Methods for the Examination of Water and Wastewater. 20th Edn., American Public Health Association, Washington, DC., USA., ISBN-13: 9780875532356, Pages: 1270.

Britz, T.J., C. Noeth and P.M. Lategan, 1988. Nitrogen and phosphate requirements for the anaerobic digestion of a petrochemical effluent. Water Res., 22: 163-169.

Bryant, M.P. and I.M. Robinson, 1961. Studies on the nitrogen requirements of some ruminal cellulolytic bacteria. Applied Microbiol., 9: 96-103.

Chan, Y.J., M.F. Chong, C.L. Law and D.G. Hassell, 2009. A review on anaerobic-aerobic treatment of industrial and municipal wastewater. Chem. Eng. J., 155: 1-18.
Cresson, R., H. Carrere, J.P. Delgenes and N. Bernet, 2006. Biofilm formation during the start-up period of an anaerobic biofilm reactor-Impact of nutrient complementation. Biochem. Eng. J., 30: 55-62.

Demirel, B. and P. Scherer, 2008. Production of methane from sugar beet silage without manure addition by a single-stage anaerobic digestion process. Biomass Bioenergy, 32: 203-209.

Demirel, B. and P. Scherer, 2011. Trace element requirements of agricultural biogas digesters during biological conversion of renewable biomass to methane. Biomass Bioenergy, 35: 992-998.

Durruty, I., N.E. Zaritzky and J.F. Gonzalez, 2012. Kinetic studies on the anaerobic degradation of soluble and particulate matter in potato wastewater. Biosyst. Eng., 111: 195-205.

Eiroa, M., J.C. Costa, M.M. Alves, C. Kennes and M.C. Veiga, 2012. Evaluation of the biomethane potential of solid fish waste. Waste Manage., 32: 1347-1352.

Fang, C., K. Boe and I. Angelidaki, 2011. Biogas production from potato-juice, a by-product from potato-starch processing, in Upflow Anaerobic Sludge Blanket (UASB) and Expanded Granular Sludge Bed (EGSB) reactors. Bioresource Technol., 102: 5734-5741.

Gerardi, M.H., 2003. The Microbiology of Anaerobic Digesters. John Wiley and Sons, New Jersey, ISBN: 9780471468950, Pages: 192.

Grady, C.P., G.T. Dagger and H.C. Lim, 1999. Biological Wastewater Treatment. 2nd Edn., Marcel Dekker, Inc., New York, USA.

Jarvis, A., A. Nordberg, T. Jarlsvik, B. Mathisen and B.H. Svensson, 1997. Improvement of a grass-clover silage-fed biogas process by the addition of cobalt. Biomass Bioenergy, 12: 453-460.

Krishnan, V., D. Ahmad and J.B. Jeru, 2008. Influence of COD: $\mathrm{N}$ : $\mathrm{P}$ ratio on dark greywater treatment using a sequencing batch reactor. J. Chem. Technol. Biotechnol., 83: 756-762.

Kumar, A., P. Miglani, R.K. Gupta and T.K. Bhattacharya, 2006. Impact of Ni(II), Zn(II) and $\mathrm{Cd}(\mathrm{II})$ on biogassification of potato waste. J. Environ. Biol., 27: 62-66.

Lasik, M., J. Nowak, M. Krzywonos and E. Cibis, 2010. Impact of batch, repeated-batch (with cell recycle and medium replacement) and continuous processes on the course and efficiency of aerobic thermophilic biodegradation of potato processing wastewater. Bioresour. Technol., 101: 3444-3451.

Lebuhn, M., F. Liu, H. Heuwinkel and A. Gronauer, 2008. Biogas production from mono-digestion of maize silage-long-term process stability and requirements. Water Sci. Technol., 58: 1645-1651. 
Lo, H.M., C.F. Chiang, H.C. Tsao, M.H. Liu and T.Y. Pai et al., 2012. Effects of spiked metals on the MSW anaerobic digestion. Waste Manage. Res., 30: 32-48.

Munk, B., C. Bauer, A. Gronauer and M. Lebuhn, 2010. Population dynamics of methanogens during acidification of biogas fermenters fed with maize silage. Eng. Life Sci., 10: 496-508.

Neves, L., R. Oliveira and M.M. Alves, 2006. Anaerobic co-digestion of coffee waste and sewage sludge. Waste Manage., 26: 176-181.

Nishio, N. and Y. Nakashimada, 2007. Recent development of anaerobic digestion processes for energy recovery from wastes. J. Biosci. Bioengineering, 103: 105-112.

Plugge, C.M., B.O. Jiang, F.A. de Bok, C. Tsai and A.J. Stams, 2009. Effect of tungsten and molybdenum on growth of a syntrophic coculture of Syntrophobacter fumaroxidans and Methanospirillum hungatei. Arch. Microbiol., 191: 55-61.

Pobeheim, H., B. Munk, H. Lindorfer and G.M. Guebitz, 2011. Impact of nickel and cobalt on biogas production and process stability during semicontinuous anaerobic fermentation of a model substrate for maize silage. Water Res., 45: 781-787.

Qiang, H., D.L. Lang and Y.Y. Li, 2012. High-solid mesophilic methane fermentation of food waste with an emphasis on Iron, Cobalt and Nickel requirements. Bioresource Technol., 103: 21-27.

Sager, M., 2007. Trace and nutrient elements in manure, dung and compost samples in Austria. Soil Biol. Biochem., 39: 1383-1390.

Scherer, P., L. Neumann, B. Demirel, O. Schmidt and M. Unbehauen, 2009. Long term fermentation studies about the nutritional requirements for biogasification of fodder beet silage as amono-substrate. Biomass Bioenergy, 33: 873-881.
Siles, J.A., M.A. Martin, A. Chica and R. Borja, 2008. Kinetic modelling of the anaerobic digestion of wastewater derived from the pressing of orange rind produced in orange juice manufacturing. Chem. Eng. J., 140: 145-156.

Speece, R.E., 1983. Anaerobic biotechnology for industrial wastewater treatment. Environ. Sci. Technol., 17: 416A-427A.

Steinhaus, B., M.L. Garcia, A.Q. Shen and L.T. Angenent, 2007. A portable anaerobic microbioreactor reveals optimum growth conditions for the methanogen Methanosaeta concilii. Applied Environ. Microbiol., 73: 1653-1658.

Sterling, M.C., R.E. Lacey, C.R. Engler and S.C. Ricke, 2001. Effects of ammonia nitrogen on $\mathrm{H}_{2}$ and $\mathrm{CH}_{4}$ production during anaerobic digestion of dairy cattle manure. Bioresource Technol., 77: 9-18.

Takashima, M. and R.E. Speece, 1989. Mineral nutrient requirements for high-rate methane fermentation of acetate at low SRT. Res. J. Water Pollut. Control Federation, 61: 1645-1650.

Vavilin, V.A., B. Fernandez, J. Palatsi and X. Flotats, 2008. Hydrolysis kinetics in anaerobic degradation of particulate organic material: An overview. Waste Manage., 28: 939-951.

Worm, P., F.G. Fermoso, P.N. Lens and C.M. Plugge, 2009. Decreased activity of a propionate degrading community in a UASB reactor fed with synthetic medium without molybdenum, tungsten and selenium. Enzyme Microb. Technol., 45: 139-145.

Zandvoort, M.H., E.D. van Hullebusch, J. Gieteling and P.N. Lens, 2006. Granular sludge in full-scale anaerobic bioreactors: Trace element content and deficiencies. Enzyme Microb. Technol., 39: 337-346. 